\title{
Chapter 6 \\ Vertical Versus Horizontal Foreign Direct Investment and Technology Spillovers
}

\subsection{Introduction}

Foreign direct investment (FDI) and international trade are two major channels of international diffusion of technological knowledge (Keller 2004,2010). While a number of empirical studies confirm significant spillover effects of knowledge through imports, the empirical findings on technology spillover effects through FDI are conflicting. In particular, there is relatively little evidence of spillovers of knowledge from inward FDI to the host country's firms in the same industry. For example, Haskel et al. (2007) examine the situation in the United Kingdom and find significantly positive productivity spillovers from FDI. In addition, Keller and Yeaple (2009) show similar results for the United States. By contrast, Aitken and Harrison (1999) and Haddad and Harrison (1993) find no significant or weak productivity spillovers from FDI for developing countries hosting FDI (the former and the latter obtain results on Venezuela and Morocco, respectively). ${ }^{1}$ Addressing the endogenous nature of the FDI decision, Lu et al. (2017) examine the spillover effects of FDI in China and find that the presence of FDI in the same industry has a significantly negative effect on the productivity levels of domestic firms due to the competition effect, while it has no significant effect on the exporting performance and research and development (R\&D) investment of domestic firms. Todo (2006) and Todo and Miyamoto (2006) derive that R\&D activities play an important role in productivity spillovers from FDI to local firms in the same industry: for example, a positive, statistically significant spillover effect is observed only for R\&D-performing foreign firms (in Indonesia) or foreign firms' R\&D stock (in Japan). In contrast, a number of studies find significant productivity spillovers from inward FDI to the host country's upstream firms through backward linkages. These studies include Javorcik (2004) for the case of Lithuania, Javorcik and Spatareanu (2008) for that of Romania, Blalock and Gertler (2008) for that of Indonesia, and Newman et al. (2015) for that of Viet-

\footnotetext{
${ }^{1}$ For example, Aitken and Harrison (1999) find negative spillover effects of FDI on the productivity of domestically owned plants in Venezuela.

(C) The Author(s) 2022

N. Jinji et al., Deep Integration, Global Firms, and Technology Spillovers,

Advances in Japanese Business and Economics 26,

https://doi.org/10.1007/978-981-16-5210-3_6
} 
nam. ${ }^{2}$ Moreover, Branstetter (2006) and Singh (2007) find evidence of technology spillovers from outward FDI. That is, firms investing in foreign countries acquire technological knowledge from other firms in the host countries.

When a firm establishes business enterprises in two or more countries through FDI, it becomes a multinational enterprise (MNE). Canonical FDI theory defines two types, namely horizontal and vertical, of FDI and an MNE's activities. ${ }^{3}$ Horizontal FDI (HFDI) replicates a subset of the production process in foreign countries to serve local markets (Brainard, 1993, 1997; Helpman et al., 2004; Markusen, 1984, 1995; Markusen and Venables, 1998, 2000). It is often motivated by an intention to reduce transportation costs. In contrast, vertical FDI (VFDI) involves geographical fragmentation of the production process and is often motivated by an intention to take advantage of factor cost differentials (Helpman, 1984, 1985; Helpman and Krugman, 1985; Venables, 1999). However, the actual patterns of FDI and an MNE's activities are much more complex than the simple dichotomy of "horizontal" and "vertical". Yeaple (2003a) constructs a model in which horizontal, vertical, and complex (i.e., both horizontal and vertical) FDI arises endogenously. Grossman et al. (2006) also analyze MNEs' integration strategies that may simultaneously involve horizontal and vertical FDI. Ekholm et al. (2007) propose the type of "export-platform FDI" as another type of FDI. Moreover, utilizing the information on sales and sourcing patterns of foreign affiliates of MNEs, Baldwin and Okubo (2014) support the importance of "networked FDI."

A number of empirical studies provide support to the predictions for HFDI. For example, Brainard (1993, 1997) obtains evidence of HFDI but little evidence of VFDI. Markusen and Maskus (2002) argue that a large proportion of FDI takes place among developed countries and is characterized by the horizontal type of FDI. Looking at the location decisions of MNEs, however, Yeaple (2003b) and Hanson et al. (2005) find evidence consistent with comparative advantage. Moreover, Alfaro and Charlton (2009) point out that the share of VFDI is much higher than previously thought even within developed countries. They argue that a significant amount of VFDI has been misclassified as horizontal in the previous studies and find that a substantial amount of VFDI between developed countries emerges in high-skill sectors, because parent firms own the stages of production proximate to their final production and source raw materials and inputs in low-skill production stages from outside of the firms.

\footnotetext{
${ }^{2}$ However, Keller (2010) argues that some issues such as a measurement problem in contractual payment between the MNEs and local firms may lead to estimation bias. Besides, Barrios et al. (2011) argue that the measures of backward linkages used in recent studies on spillovers are potentially problematic. Using the standard measures employed in the literature, they fail to find robust evidence for spillovers through backward linkages. On the other hand, they obtain robust evidence for positive FDI backward spillover effects.

${ }^{3}$ See Markusen (1995), Markusen (2002), Markusen and Maskus (2003), and Helpman (2006) for the survey of the literature.
} 
A literature that is separated from studies on FDI has shown the importance of international fragmentation of production and the involvement of firms in international production networks (or global value chains $(\mathrm{GVC}))^{4}$

Depending on the type of FDI or the degree of involvement in GVC, affiliates of MNEs conduct different activities in their host economies, affecting the extent of technology spillovers between MNEs and domestic firms in the host economies. For example, when MNEs conduct VFDI, foreign affiliates engage in intra-firm trade with their parent firms in the source country. On the other hand, in the case of networked FDI, foreign affiliates are involved in GVC and are likely to trade with other affiliates in the same region. Ramondo et al. (2016) document that intra-firm trade is concentrated on a small group of large foreign affiliates of MNEs headquartered in the United States. They find that the median manufacturing foreign affiliate of the US MNEs has no transaction of goods with its parent in the United States. This finding suggests that VFDI is concentrated on large firms and large affiliates. ${ }^{5}$ To the best of our knowledge, no existing studies have investigated how the type of FDI or the degree of involvement in GVC affects technology spillovers between MNEs and their host economies.

An empirical work by Branstetter (2006) is closely related to the analysis in this chapter. He defines the term "technology spillovers" as "the process by which one inventor learns from the research outcomes of others' research projects and is able to enhance her own research productivity with this knowledge without fully compensating the other inventors for the value of this learning" (pp. 327-328). In this sense, technology spillovers must be distinguished from the term "productivity spillovers" which measures how productivity of a firm is affected by other firms' one or R\&D activities. Then, in the literature with respect to spillovers, patent citation data have been used as a proxy of technology spillovers in the above definition (Jaffe et al. 1993). ${ }^{6}$ Branstetter (2006) analyzes firm-level data on Japanese MNEs in the United States and patent citations at the United States Patent and Trademark Office (USPTO) and obtains evidence that FDI facilitates technology spillovers both from investing firms to local firms in the host country and from the local firms to the investing firms. Although he examines whether different types of FDI, such as acquisition, greenfield investment, and R\&D facilities, have different effects on spillovers, he does not distinguish various production activities of foreign affiliates.

\footnotetext{
${ }^{4}$ See Antràs and Chor (2013), Baldwin and Venables (2013), and Costinot et al. (2013) for theoretical work and Alfaro et al. (2019) and Timmer et al. (2014) for empirical evidence. See Amador and Cabral (2016) for the survey of the literature.

${ }^{5}$ The finding by Ramondo et al. (2016) is related to the observation by Atalay et al. (2014) for production chains within the United States. In particular, they show that the ownership of vertically linked affiliates is not related to the transfer of goods within the boundaries of the firm. Ramondo et al. (2016)) argue that the vertical ownership promotes efficient intra-firm transfers of intangible inputs.

${ }^{6}$ There are a number of existing empirical studies on technology spillovers based on patent citations (Cappelli and Montobbio, 2020; Haruna et al., 2010; Hu and Jaffe, 2003; Jaffe and Trajtenberg, 1999; Jinji et al., 2013, 2015, 2019a; Li, 2014; MacGarvie, 2006; Mancusi, 2008; Murata et al., 2014; Peri, 2005).
} 
In this chapter, we attempt to identify how the structure of MNEs' activities in terms of horizontal and vertical FDI affects technology spillovers between MNEs and host countries. Then, we combine a comprehensive firm-level dataset of the business activities of Japanese MNEs' foreign affiliates and information on the patent citations between MNEs and their host countries. Following Branstetter (2006), we define "technology spillovers" as the effects on the research productivity from the outcomes of others' research activities without full compensation for the value of research productivity enhancement. ${ }^{7}$ Alternatively, we use firm-level data on Japanese firms' FDI and patent citations at the USPTO. ${ }^{8}$ Our firm-level dataset includes information on the sales and purchases of the foreign affiliates, classified according to the destination and source countries. We exploit this information to construct new measures of horizontal and vertical FDI based on the shares of the host and home countries in their transactions. Now we define a measure of "pure horizontal FDI" as the extent to which affiliates' purchases of intermediate inputs and sales of final goods are concentrated in the local market. We also define a measure of "pure vertical FDI" as the extent to which their affiliates' purchases of intermediate inputs and sales of final goods are linked to the home country. We, furthermore, define measures of "partially horizontal" and "partially vertical" FDI. We then estimate how different types of FDI affect technology spillovers from Japanese MNEs to the host country and from the host country to Japanese MNEs. As for the empirical methodology, we follow Branstetter (2006). Since the dependent variable (i.e., patent citations) is the count data, we utilize a negative binomial model developed by Hausman et al. (1984). Moreover, to deal with a potential endogeneity problem we employ an endogenous switching model discussed by Miranda and Rabe-Hesketh (2006).

Our main findings are as follows. We find that an increase in the degree of pure VFDI has significantly positive effects on technology spillovers captured by patent citations when technologically advanced economies host Japanese MNEs. Technology spillovers occur in both directions between the MNEs and their host countries. These positive effects of pure VFDI on technology spillovers are robust for different specifications as well. Partially VFDI (i.e., FDI with a higher share of purchase of intermediate inputs in the local market and a higher share of sales of outputs to the home country) also has significantly positive effects on technology spillovers from the (high-income) host countries to the MNEs. ${ }^{9}$ By contrast, an increase in the degree of pure HFDI has no significant effect or significantly negative effects on technology spillovers between the MNEs and their host countries. Partially HFDI (i.e., FDI with a higher share of purchases from the home country and a higher share of sales to

\footnotetext{
${ }^{7}$ Therefore, our definition of technology spillovers is narrower than that used in studies on the productivity change due to FDI or trade. However, it seems that our definition is useful, because it focuses on direct effects and can still capture an important part of the effects in terms of the contribution to the expansion of the world's technology frontier.

${ }^{8}$ We acknowledge that the range of technology spillovers measured in the data may be narrowed, particularly for developing countries, by using patent citations, because many indigenous firms in developing countries are not so active in the application of patents.

${ }^{9}$ The positive effects of partially VFDI are not robust when we employ different specifications, although we do not report the details of the estimated results in this chapter.
} 
the local market) has significantly positive effects on technology spillovers from the MNEs to the (high-income) host countries, but the result is not robust for different estimations. From these results, we conclude that pure VFDI plays a dominant role in technology spillovers in both directions between Japanese MNEs and the high-income host countries.

To explain the mechanism for the observed relationship between the structure of FDI and technology spillovers, we develop a simple partial-equilibrium model of FDI and technology spillovers among developed countries. A differentiated good is produced in three stages. ${ }^{10}$ The product market is characterized by monopolistic competition. Depending on parameter values, firms may have an incentive to engage in horizontal or vertical FDI. Assuming that factor costs are the same in the two countries, there is no possibility of VFDI in the usual sense. Nevertheless, VFDI does occur if there are technology gaps in some production stages between the two countries and/or if firms can take advantage of the superior technology by fragmenting their production process abroad. Technological differences in some production stages are considered to be the source of technology spillovers through FDI. We show that technology spillovers occur in one way or two ways if firms engage in VFDI, depending on how the three production stages are located in the two countries. Besides, we show that HFDI does not necessarily induce technology spillovers, because it is mainly motivated by saving transportation costs and hence appears even in the absence of technological differences.

The rest of this chapter is organized as follows. Section 6.2 describes the data employed in our empirical analysis. Section 6.3 introduces estimation methods. Section 6.4 provides empirical results. Section 6.5 develops a simple theoretical model of FDI and technology spillovers to explain the observed relationship in our empirical study. Section 6.6 concludes this chapter.

\subsection{Data}

In this section we describe the data employed in our empirical analysis.

\subsubsection{Data on Patent Citations and Japanese Firms' FDI}

Following Jaffe et al. (1993), Jaffe and Trajtenberg (1999), and other studies, we use patent citation data as a proxy for technology spillovers. The patent citations are collected from the dataset compiled by the National Bureau of Economic Research

\footnotetext{
${ }^{10}$ As the models of vertical production structure with multiple stages there are, for example, Bridgman (2012), Dixit and Grossman (1982), Kohler (2004), and Yi (2003). None of these papers, however, consider the possibility of VFDI driven by cross-country technology gaps in production stages. Baldwin and Venables (2013) consider more general structure of the GVC in production processes.
} 
(NBER) patent database for patents at the USPTO. ${ }^{11}$ The dataset includes information on the application date, the country name of the assignee, the main US patent class, and citations made and received for each patent. From the dataset we extract information on the patent applications and citations by Japanese MNEs and their host countries. Because of the truncated problems of citations in the NBER dataset, we concentrate our analysis on the period before 2003, though the NBER patent dataset includes data until 2006.

Our data on Japanese MNEs' activities abroad are obtained from the Basic Survey on Overseas Business Activities (BSOBA) or Kaigai Jigyo Katsudo Kihon Chosa conducted by the Japanese Ministry of Economic, Trade and Industry (METI). This data source provides detailed data on affiliate-level FDI activities such as the sales and purchases of affiliates of Japanese MNEs, classified by their destinations and sources, i.e., sales to (or purchases from) the local market or exports to (or imports from) the home country and a third country.

The foreign affiliates listed in the BSOBA are either foreign affiliates with at least $10 \%$ of their capital held by a Japanese parent company or those with at least $50 \%$ of their capital held by a foreign subsidiary, which in turn has at least $50 \%$ of its capital held by a Japanese parent company. These affiliates exclude those that run businesses in the financial and insurance industry or the real estate industry in host countries. According to the METI, there were approximately 15,000 foreign affiliates that responded to the survey in 2000. ${ }^{12}$ Table 6.1 shows the top 30 host economies for Japanese MNEs in 2000, based on the number of affiliates that had completed the BSOBA. ${ }^{13}$ As shown in the table, the United States attracts the largest number of Japanese firms' affiliates, followed by China. Asian economies as well as developed countries are popular host economies for Japanese MNEs.

Our sample covers the period between 1995 and 2003. All countries in which Japanese MNEs have at least one affiliate are included in our sample. Since the number of countries varies greatly depending on that of patent applications made, we divide our sample of the countries into two groups, Groups I and II, according to the number of USPTO patent applications made by the sample countries during the period of 1995-2003. We call Group I countries/economies "Technologically Advanced Economies," which mainly include high income countries/economies. In contrast, we call Group II countries/economies "Technologically Less Advanced Economies," which mainly include middle and low income countries. The number of patent applications in Group I is larger than 1,000, while it is less than that in Group II. ${ }^{14}$ All countries that are categorized into each group are listed in Table 6.2.

\footnotetext{
${ }^{11}$ See the Bronwyn Hall's website (www.nber.org/people/bronwyn_hall?page=1\&perPage=50) for the NBER patent database.

${ }^{12}$ See the METI website (www.meti.go.jp/english/statistics/tyo/kaigaizi/index.html) for the details of the BSOBA.

${ }^{13}$ About 10,100 affiliates reported full or partial information on their sales and purchases classified by the destinations and the sources in 2000 .

${ }^{14}$ Although the number of USPTO patent applications made by China, India, Russia, and Singapore is more than 1,000 during the period, a large jump in the applications is observed after 2000,
} 
Table 6.1 Top 30 FDI host countries/economies in the year 2000

\begin{tabular}{l|l|l|l|l|l}
\hline Economy & No. of affiliates & Economy & No. of affiliates & Economy & No. of affiliates \\
\hline United States & 2,172 & Australia & 342 & India & 99 \\
\hline China & 1,246 & Korea & 257 & Vietnam & 97 \\
\hline Thailand & 692 & Netherlands & 248 & Belgium & 80 \\
\hline Singapore & 613 & France & 216 & New Zealand & 74 \\
\hline Hong Kong & 585 & Canada & 196 & Chile & 42 \\
\hline United & 509 & Brazil & 193 & & \\
Kingdom & & & & & \\
\hline Malaysia & 477 & Panama & 138 & & \\
\hline Taiwan & 460 & Mexico & 132 & & \\
\hline Indonesia & 431 & Italy & 114 & & \\
\hline Germany & 363 & Spain & 100 & &
\end{tabular}

Note: The number of affiliates is those reported by respondents of the BSOBA in 2000

Table 6.2 List of countries/economies

\begin{tabular}{l|l|l|l|l}
\hline Group I & \multicolumn{4}{ll}{ Group II } \\
\hline (Tech. Advanced Economies) & (Technologically Less Advanced Economies) \\
\hline Australia & Argentina & Ghana & Niger & Trinidad\&Tobago \\
\hline Austria & Bahamas & Greece & Nigeria & Tunisia \\
\hline Belgium & Bahrain & Guatemala & Pakistan & Turkey \\
\hline Canada & Bangladesh & Hong Kong & Panama & UAE \\
\hline Denmark & Bolivia & Hungary & $\begin{array}{l}\text { Papua New } \\
\text { Guinea }\end{array}$ & Uruguay \\
\hline Finland & Brazil & Iceland & Paraguay & Venezuela \\
\hline France & Brunei & India & Peru & Vietnam \\
\hline Germany & Cambodia & Indonesia & Poland & Zambia \\
\hline Israel & Cameroon & Iran & Portugal & Zimbabwe \\
\hline Italy & Chile & Ireland & Qatar & \\
\hline Korea, Republic of & China & Jamaica & Romania & \\
\hline Luxembourg & Colombia & Kenya & Russia & \\
\hline Netherlands & Costa Rica & Kuwait & Samoa & \\
\hline New Zealand & Cyprus & Laos & Saudi Arabia & \\
\hline Norway & Czech & Lebanon & Senegal & \\
\hline Spain & Dominican & Liberia & Singapore & \\
\hline Sweden & Ecuador & Macao & Slovak & \\
\hline Switzerland & Egypt & Madagascar & South Africa & \\
\hline Taiwan & El Salvador & Malaysia & Sri Lanka & \\
\hline United Kingdom & Ethiopia & Mexico & Tanzania & \\
\hline United States & Fiji & Morocco & Thailand & \\
\hline & & & &
\end{tabular}


We use the Nikkei company code system to link the two data sources and collected the data on 1,445 parent companies that run at least one affiliate during the sample period. 279 parent companies out of 1,445 ones made at least one citation to USPTO patent applications from 93 countries and, on the other hand, 301 ones received at least one USPTO patent citation.

\subsubsection{Types of FDI}

In the literature, FDI and MNEs' activities are usually categorized into horizontal and vertical cases. In the empirical studies, there are a number of ways to measure horizontal and vertical FDI. Hummels et al. (2001) and Alfaro and Charlton (2009) use the industrial classifications to define the types of FDI. Hanson et al. (2001, 2005) utilize the firm-level database of the United States Bureau of Economic Analysis (BEA) to characterize VFDI as intra-firm flows of inputs that they observed flowing from parent companies in the United States to affiliates abroad. The method of Hanson et al. (2001, 2005) enables them to measure one-way US bilateral intra-firm trade. Using the same BSOBA dataset as in this chapter, Fukao and Wei (2008) employ the local sales ratio of the affiliates to classify vertical and horizontal FDI. In particular, if a local sales ratio of a foreign affiliate is less than the average ratio in the sample, then FDI to the affiliate is classified into VFDI. By contrast, if a local sales ratio is larger than the average ratio, FDI to the affiliate is classified into HFDI.

An advantage of the BSOBA dataset is that it allows us to measure vertical and horizontal FDI by using information on the sale of outputs and the purchase of inputs by foreign affiliates. ${ }^{15}$ The local sales and local purchases ratios of foreign affiliates of Japanese MNEs are denoted by $S h S a H F D I$ and $S h P u H F D I$, respectively. Similarly, the sales and purchases ratios to and from Japan for foreign affiliates of Japanese MNEs are denoted by ShSaVFDI and ShPuVFDI, respectively. Table 6.3 shows the average values of both ratios during the sample period for the subsamples of technologically advanced and less advanced economies. Looking at the ratios over the years, no evident trend is observed during the sample period. Interestingly, the table also shows that the values of $\operatorname{Sh} S a V F D I$, which indicates the vertical structure of sales from foreign affiliates, are around 10-12\% in technologically advanced economies and around 20-22\% in technologically less advanced economies. If we focus on $S h P u V F D I$ (i.e., the vertical structure of purchases by foreign affiliates), then the values climb up to around $40-42 \%$ in technologically advanced economies and $37-40 \%$ in technologically less advanced economies. With respect to the pur-

compared with a very limited number in the early years for these countries. We therefore categorize these four countries into the second group.

15 One limitation of the BSOBA dataset is, however, that it does not track transactions between foreign affiliates or between foreign affiliates and the parent companies. As a result, there may exist some biases for measuring the types of FDI by using information on sale and purchase because we cannot examine flows within the boundary of a firm from our dataset. 
Table 6.3 Sales and purchases ratios of affiliates abroad

\begin{tabular}{l|c|c|c|c|c|c|c|c|c}
\hline & 1995 & 1996 & 1997 & 1998 & 1999 & 2000 & 2001 & 2002 & 2003 \\
\hline & \multicolumn{7}{l}{ Tech. advanced economies (Group I) } \\
\hline ShSaHFDI & 0.761 & 0.747 & 0.735 & 0.757 & 0.761 & 0.759 & 0.751 & 0.752 & 0.745 \\
\hline ShSaVFDI & 0.128 & 0.125 & 0.126 & 0.127 & 0.126 & 0.122 & 0.124 & 0.106 & 0.107 \\
\hline ShPuHFDI & 0.530 & 0.493 & 0.474 & 0.501 & 0.481 & 0.481 & 0.490 & 0.464 & 0.462 \\
\hline ShPuVFDI & 0.403 & 0.398 & 0.405 & 0.413 & 0.424 & 0.421 & 0.420 & 0.404 & 0.403 \\
\hline \multicolumn{8}{l}{ Tech. loss advanced economies (Group II) } \\
\hline ShSaHFDI & 0.655 & 0.649 & 0.612 & 0.639 & 0.644 & 0.636 & 0.630 & 0.631 & 0.631 \\
\hline ShSaVFDI & 0.208 & 0.197 & 0.211 & 0.222 & 0.212 & 0.212 & 0.228 & 0.204 & 0.208 \\
\hline ShPuHFDI & 0.524 & 0.482 & 0.464 & 0.512 & 0.494 & 0.493 & 0.509 & 0.530 & 0.536 \\
\hline ShPuVFDI & 0.392 & 0.395 & 0.401 & 0.405 & 0.407 & 0.402 & 0.403 & 0.370 & 0.369 \\
\hline
\end{tabular}

Source: Authors' calculation from the BSOBA data from 1995 to 2003

chase of inputs, Japanese MNEs engage in VFDI more actively in technologically advanced host countries than in technologically less advanced host countries. This evidence is consistent with Alfaro and Charlton (2009), who showed that VFDI emerges as far more prevalent between developed countries.

By exploiting information on the horizontal and vertical structures in sales and purchases of foreign affiliates, we construct new indexes of horizontal and vertical FDI, i.e., $H F D I, V F D I, P H F D I$, and $P V F D I$, in the following way:

$$
\begin{aligned}
H F D I & =S h S a H F D I \times S h P u H F D I \\
V F D I & =S h S a V F D I \times S h P u V F D I \\
P H F D I & =S h S a H F D I \times S h P u V F D I \\
P V F D I & =S h S a V F D I \times S h P u H F D I
\end{aligned}
$$

As is evident from the definition of the index, $H F D I$ measures the extent to which affiliates' purchases of intermediate inputs and sales of final goods are concentrated in the local market. Now, $H F D I$ captures the degree of "pure" HFDI. If $H F D I=1$, a foreign affiliate makes all purchases and sales in the local market, whereas, if $H F D I=0$, either or both of purchases and sales of the foreign affiliate become zero in the local market. Note that $H F D I=0$ does not necessarily mean that the foreign affiliate engages in vertical activities because there is a possibility of transactions with third countries. Next VFDI measures the extent to which affiliates' purchases of intermediate inputs and sales of final goods are linked to the home country (i.e., Japan), so that $V F D I$ captures the degree of "pure" VFDI. On the other hand, PHFDI and PVFDI capture "partially" horizontal and "partially" vertical FDI, respectively. The value of $P H F D I$ rises if an affiliate buys more intermediate goods from the home country and sells more final goods to the local market. Since the structure of sales is more important to distinguish the type of FDI than the structure of purchases, we consider that P H F DI measures the degree of "partially" horizontal 
FDI in terms of its horizontal sales structure. Similarly, the value of $P V F D I$ becomes large if an affiliate buys more intermediate goods from the local market and sells more final goods to the home country. Since the structure of sales is vertical in $P V F D I$, we consider that it measures the degree of "partially" vertical FDI.

We then test whether there are any differences in the effects on technology spillovers among these types of FDI.

\subsection{The Empirical Model}

In this section, let us explain our empirical model. Although the BSOBA is conducted every year, there are many blanks in the data on a particular firm because in some years certain respondents did not report to the METI. For this reason, we use only a pooled data in our estimation. Consequently, we run the following specification as in Branstetter (2006),

$$
C_{i}=\beta_{1}+\alpha_{1} \text { LPHost }_{i}+\alpha_{2} \text { LPParent }_{i}+\beta_{2} \text { FDI }_{i}+u_{i},
$$

where $i$ refers to the affiliate $i$, and $C_{i}$ is the number of citations made (or received) by USPTO patents of the Japanese parent company that owns affiliate $i$. Note that $C_{i}=C_{i^{\prime}}$ holds for affiliate $i$ and affiliate $i^{\prime}$ if the same parent company owns affiliates $i$ and $i^{\prime}$. We expect that citations made by Japanese parent companies capture the technology spillovers flowing from the host countries to Japanese companies, while the citations received by them reflect the flows from Japanese companies to host countries. $F D I_{i}$ in Eq. (6.1) is one of the alternative measures of the FDI types, i.e., $H F D I, V F D I, P H F D I$, and $P V F D I$ for affiliate $i$. In Eq. (6.1), $\beta_{1}$ is a constant term and $u_{i}$ is an error term.

As indicated in Branstetter (2006), patent citations may rise as the "citable" host invention increases. At the same time, the higher absorptive capacity in the home country may be associated with a higher ability to understand and exploit external knowledge, and cite more external patents (Mancusi, 2008). Thus, for elucidation of the assertions we use LP Parent $t_{i}$ and LPHost ${ }_{i}$, which refer to the logarithm of the count of the USPTO patent applications made by affiliate $i$ 's Japanese parent company and the host country where the affiliate $i$ runs its business, respectively, to proxy the home absorptive capacity and "citable" host invention. Note that LP Parent is $_{i}$ the same across affiliate $i$ for the same parent company, and LPHost $t_{i}$ is the same across affiliate $i$ for the same host country.

The focus of interest in Eq. (6.1) will be the coefficient $\beta_{2}$. Hence, we examine if the FDI types of Japanese firms in host countries have an influence on patent citations made and received by the firm. We also investigate if there is a difference in the magnitude and sign of the coefficients between the citations made and received by the home and host countries and across the types of FDI that Japanese firms implemented. 
Since the observations of a dependent variable (i.e., patent citations) are the count data, we utilize a standard estimation technique, namely, a negative binomial model discussed in Cameron and Trivedi (1998), where the data are Poisson process, but more flexible modeling of the variance to account for overdispersion than the Poisson is allowed. We use this estimation technique to acquire our basic findings and alternative estimation results.

The other challenge of estimating the effects of each of the FDI types on technology spillovers arises from the fact that patent citations may be endogenous, because unobservables in determining the types of FDI may be correlated with those in determining the citations. Besides, certain geographic factors such as distance and language may influence the citations as well as the types of FDI. Neglecting these unobserved or endogenous factors may cause biased and inconsistent estimators. ${ }^{16}$ To address this issue, we employ an endogenous switching model. ${ }^{17}$ In that model, the citation $C_{i}$ follows a Poisson distribution, and the probability distribution for count data is given by

$$
\operatorname{Pr}\left(C_{i}, \mu_{i}\right)=\frac{\mu_{i}{ }^{C_{i}} \exp \left(-\mu_{i}\right)}{C_{i} !},
$$

so that a log-linear model for the mean of $C_{i}, \mu_{i}$, can be specified as

$$
\begin{aligned}
\log \left(\mu_{i}\right)= & \beta_{1}+\alpha_{1} \text { LPHost }_{i}+\alpha_{2} \text { LPP Prent }_{i}+\alpha_{3} \text { LDist }_{i}+\alpha_{4} L G D P_{i} \\
& +\alpha_{5} \text { LCost }_{i}+\beta_{2} D_{i}+\epsilon_{i},
\end{aligned}
$$

where $L D i s t_{i}$ is the logarithm of the distance (measured as kilometers) between Japan and the host economy of affiliate $i, L G D P_{i}$ is the logarithm of GDP of affiliate $i$ 's host economy, $L \operatorname{Cos}_{i}$ is the logarithm of salary per employee of affiliate $i$, and $\epsilon_{i}$ is an unobserved heterogeneity term. $L G D P_{i}$ measures the market size of the host economy, and $L$ Cost $_{i}$ measures the labor cost of the affiliate. Instead of $F D I_{i}$ in Eq. (6.1), here we use a dummy $D_{i}\left(D_{H F D I_{i}}, D_{V F D I_{i}}, D_{P H F D I_{i}}\right.$, or $\left.D_{P V F D I_{i}}\right)$ for the types of FDI, which equals one for a particular type, and zero otherwise. Following Fukao and Wei (2008), we construct the dummy for a particular type of FDI such that it equals one when the value of an FDI type's index (HFDI, VFDI, PHFDI, or $P V F D I$ ) for affiliate $i$ is greater than the average value of the particular FDI type's index in the full sample, and zero otherwise. We then use a probit model to examine how a parent firm determines its FDI type. The logic we use is that the type decision on FDI depends on factors that favor a particular type of FDI or not. The probit model can be formulated as

$$
D_{i}^{*}=z_{i}^{\prime} \gamma+\lambda \epsilon_{i}+u_{i}
$$

\footnotetext{
16 See Wooldridge (2010) for dealing with endogenous problems.

17 An estimation method of count data regression with endogenous switching is proposed by Terza (1998). Kenkel and Terza (2001) discuss an application of the method suggested by Terza (1998). See Miranda and Rabe-Hesketh (2006) for technical details of the endogenous switching model.
} 
and

$$
D_{i}= \begin{cases}1, & \text { if } D_{i}^{*}>0 \\ 0, & \text { otherwise }\end{cases}
$$

where $D_{i}^{*}$ is an auxiliary random variable, $z_{i}$ is a vector of factors which may influence the particular type of FDI. As usual, we have $u_{i} \sim N(0,1)$, and $u_{i}$ is independent of $\epsilon_{i}$. In the so-called endogenous switching model, $\operatorname{Var}\left(\epsilon_{i}\right)=\sigma^{2}$, and total variance is $\lambda^{2} \sigma^{2}+1$. If $\lambda=0$, then $D_{i}$ is considered to be exogenous. Although a Poisson distribution is used, the variance of $C_{i}$ is not necessarily equal to the conditional mean, and overdispersion is allowed in this model. Using the normality assumption for $\epsilon_{i}$, we have

$$
\operatorname{Var}\left(C_{i} \mid x_{i}, D_{i}\right)=E\left(C_{i} \mid \epsilon_{i}, x_{i}, D_{i}\right)\left[1+E\left(C_{i} \mid \epsilon_{i}, x_{i}, D_{i}\right)\left(\exp \left(\sigma^{2}\right)-1\right)\right],
$$

where $x_{i}$ is a vector of explanatory variables in Eq. (6.3) (i.e., LP Host $t_{i}, L P$ Parent $t_{i}$, $L D i s t_{i}, L G D P_{i}, L \operatorname{Cost}_{i}$, and the constant term), which implies that if $\sigma \neq 0$, then the model exhibits overdispersion, as we would expect from the negative binomial model in Eq. (6.1). ${ }^{18}$

In the estimation, following Fukao and Wei (2008), we include LDist $t_{i}$ (distance), $L G D P_{i}$ (market size), and $L$ Cost $t_{i}$ (labor cost) in $z_{i}$ in Eq. (6.4). Among those variables, the data on salaries and the number of employees of foreign affiliates are obtained from the BSOBA. The data on distance are collected from the database of the CEPII Research Center and the data on GDP in host countries are obtained from the Penn World Table. ${ }^{19}$

\subsection{Empirical Results}

In this section, we report our estimation results. We first show the basic findings obtained by the negative binomial model. We then report the results by the endogenous switching model and discuss whether the endogeneity issue matters in our analysis. Finally, we discuss the robustness of our findings by showing the results of alternative estimations with additional explanatory variables.

\subsubsection{Basic Findings}

We first estimate Eq. (6.1) by the negative binomial model, and the results are reported in Table 6.4. The upper panel of Table 6.4 shows the estimated results for the sub-

\footnotetext{
${ }^{18}$ See Miranda and Rabe-Hesketh (2006) for more details.

${ }^{19}$ CEPII: www.cepii.fr/CEPII/en/bdd_modele/presentation.asp?id=6. Penn World table: $w w w . r u g$. $\mathrm{nl} / \mathrm{ggdc} /$ productivity/pwt/.
} 
Table 6.4 Negative binomial estimates for patent citations

\begin{tabular}{|c|c|c|c|c|c|c|c|c|}
\hline \multirow[b]{3}{*}{$H F D I$} & \multicolumn{8}{|c|}{ Tech. advanced economies (Group I) } \\
\hline & \multicolumn{4}{|l|}{ Citing } & \multicolumn{4}{|l|}{ Cited } \\
\hline & $\begin{array}{l}-0.172^{* * *} \\
(0.029)\end{array}$ & & & & $\begin{array}{l}-0.480^{* * *} \\
(0.047)\end{array}$ & & & \\
\hline$V F D I$ & & $\begin{array}{l}0.529^{* * *} \\
(0.085)\end{array}$ & & & & $\begin{array}{l}1.273^{* * *} \\
(0.15)\end{array}$ & & \\
\hline PHFDI & & & $\begin{array}{l}-0.005 \\
(0.025)\end{array}$ & & & & $\begin{array}{l}0.197^{* * *} \\
(0.045)\end{array}$ & \\
\hline$P V F D I$ & & & & $\begin{array}{l}0.115^{*} \\
(0.064)\end{array}$ & & & & $\begin{array}{l}-0.120 \\
(0.092)\end{array}$ \\
\hline LPHost & $\begin{array}{l}0.982^{* * * *} \\
(0.006)\end{array}$ & $\begin{array}{l}0.976^{* * *} \\
(0.005)\end{array}$ & $\begin{array}{l}0.973^{* * *} \\
(0.005)\end{array}$ & $\begin{array}{l}0.973^{* * * *} \\
(0.006)\end{array}$ & $\begin{array}{l}1.106^{* * *} \\
(0.009)\end{array}$ & $\begin{array}{l}1.087^{* * *} \\
(0.009)\end{array}$ & $\begin{array}{l}1.083^{* * *} \\
(0.009)\end{array}$ & $\begin{array}{l}1.081^{* * *} \\
(0.009)\end{array}$ \\
\hline$L P$ Parent & $\begin{array}{l}0.963^{* * *} \\
(0.005)\end{array}$ & $\begin{array}{l}0.963^{* * * *} \\
(0.005)\end{array}$ & $\begin{array}{l}0.960^{* * *} \\
(0.005)\end{array}$ & $\begin{array}{l}0.966^{* * *} \\
(0.005)\end{array}$ & $\begin{array}{l}0.502^{* * *} \\
(0.003)\end{array}$ & $\begin{array}{l}0.503^{* * *} \\
(0.003)\end{array}$ & $\begin{array}{l}0.500^{* * *} \\
(0.003)\end{array}$ & $\begin{array}{l}0.506^{* * *} \\
(0.003)\end{array}$ \\
\hline No. of Obs & 14836 & 14568 & 15441 & 14026 & 14836 & 14568 & 15441 & 14026 \\
\hline $\begin{array}{l}\text { Log } \\
\text { likelihood }\end{array}$ & -24646 & -24059 & -25682 & -23157 & -33957 & -33306 & -35403 & -32028 \\
\hline \multirow[t]{3}{*}{ Prob $>$ chi $^{2}$} & 0.00 & 0.00 & 0.00 & 0.00 & 0.00 & 0.00 & 0.00 & 0.00 \\
\hline & \multicolumn{8}{|c|}{ Tech. Less Advanced Economies (Group II) } \\
\hline & \multicolumn{4}{|c|}{ Citing } & \multicolumn{4}{|l|}{ Cited } \\
\hline$H F D I$ & $\begin{array}{l}-0.573^{* * *} \\
(0.11)\end{array}$ & & & & $\begin{array}{l}-0.684^{* * *} \\
(0.10)\end{array}$ & & & \\
\hline$V F D I$ & & $\begin{array}{l}0.189 \\
(0.24)\end{array}$ & & & & $\begin{array}{l}0.182 \\
(0.20)\end{array}$ & & \\
\hline$P H F D I$ & & & $\begin{array}{l}-0.033 \\
(0.11)\end{array}$ & & & & $\begin{array}{l}-0.338^{* * *} \\
(0.10)\end{array}$ & \\
\hline$P V F D I$ & & & & $\begin{array}{l}1.087^{* * *} \\
(0.21)\end{array}$ & & & & $\begin{array}{l}0.938^{* * * *} \\
(0.17)\end{array}$ \\
\hline LPHost & $\begin{array}{l}1.095^{* * *} \\
(0.023)\end{array}$ & $\begin{array}{l}1.085^{* * *} \\
(0.022)\end{array}$ & $\begin{array}{l}1.082^{* * *} \\
(0.022)\end{array}$ & $\begin{array}{l}1.081^{* * *} \\
(0.023)\end{array}$ & $\begin{array}{l}1.097^{* * *} \\
(0.020)\end{array}$ & $\begin{array}{l}1.112^{* * *} \\
(0.020)\end{array}$ & $\begin{array}{l}1.109^{* * *} \\
(0.020)\end{array}$ & $\begin{array}{l}1.088^{* * *} \\
(0.020)\end{array}$ \\
\hline$L P$ Parent & $\begin{array}{l}1.021^{* * *} \\
(0.023)\end{array}$ & $\begin{array}{l}1.018^{* * *} \\
(0.023)\end{array}$ & $\begin{array}{l}1.022^{* * *} \\
(0.023)\end{array}$ & $\begin{array}{l}1.037^{\text {*** }} \\
(0.024)\end{array}$ & $\begin{array}{l}0.932^{* * *} \\
(0.019)\end{array}$ & $\begin{array}{l}0.934^{* * *} \\
(0.019)\end{array}$ & $\begin{array}{l}0.934^{* * *} \\
(0.019)\end{array}$ & $\begin{array}{l}0.949^{* * *} \\
(0.020)\end{array}$ \\
\hline $\begin{array}{l}\text { No. of } \\
\text { Obs. }\end{array}$ & 18928 & 18870 & 19345 & 18397 & 18928 & 18870 & 19345 & 18397 \\
\hline $\begin{array}{l}\text { Log } \\
\text { likelihood }\end{array}$ & -3836 & -3917 & -3988 & -3755 & -5732 & -5795 & -5919 & -5604 \\
\hline Prob $>$ chi $^{2}$ & 0.00 & 0.00 & 0.00 & 0.00 & 0.00 & 0.00 & 0.00 & 0.00 \\
\hline
\end{tabular}

Notes: (a) $* * *, * *$, and $*$ indicate significance at the $1 \%, 5 \%$, and $10 \%$ levels, respectively

(b) The values in the parentheses are standard errors

(c) A constant term is included in the estimations 
sample of technologically advanced economies. We observe from the results that the estimates of $H F D I$ are significant and negative, whereas they are significantly positive for $V F D I$ both for the citing and cited. As for $P H F D I$, the estimated coefficient is insignificant for the citing, but significantly positive for the cited, whereas the coefficient of $P V F D I$ are significant and positive for the citing and insignificant for the cited.

The lower panel of Table 6.4 presents the estimated results for the subsample of technologically less advanced economies. Unlike the case of the technologically advanced economies, only the coefficients on $P V F D I$ show significantly positive, whereas the coefficients of the other types of FDI reveal negative or insignificant effects on the citing as well as the cited.

These results show that an increase in the degree of the "pure" VFDI has a significantly positive effect on technology spillovers in both directions between Japanese parent companies and their host countries if Japanese MNEs invest in high-income countries. This implies that VFDI plays a dominant role in technology spillovers with mutual effects in technologically advanced economies. When middle- and lowincome countries host Japanese MNEs, an increase in the "partially" vertical FDI has a significantly positive effect on the number of patent citations in both directions between the Japanese parent companies and firms in their host countries.

\subsubsection{Estimating with an Endogenous Switching Model}

To deal with endogeneity issues, we simultaneously estimate both an endogenous switching model described by Eqs. (6.2) and (6.3) for technology spillovers and a probit model based on Eq. (6.4) for the decision on FDI types. We focus on the subsample of technologically advanced economies. The estimated results are summarized in Table 6.5. We first observe that the coefficient of LCost is significantly positive for both "pure" VFDI $\left(D_{V F D I}\right)$ and "partially" vertical FDI ( $\left.D_{P V F D I}\right)$. This implies that VFDI to technologically advanced economies is not motivated by wage cost saving.

In terms of the endogeneity between technology spillovers and the decision on FDI types, the estimates of $\rho$ in Table 6.5 show strong significance against the null hypothesis in two cases out of eight estimations for technologically advanced economies and in all cases for technologically less advanced economies. ${ }^{20}$ Consequently, neglecting the endogenous issues may cause biased and inconsistent estimators (Miranda and Rabe-Hesketh, 2006). The estimations in Table 6.5 reveal that $D_{V F D I}$ based on the endogenous switching model for both the citing and cited cases provides results similar to those based on the negative binomial model. For $D_{P V F D I}$, the two models also provide similar results, suggesting that more local purchases and more sales in Japan may favor Japanese parent companies with more technology spillovers from

\footnotetext{
${ }^{20}$ Now $\rho$ stands for the correlation between $\epsilon_{i}$ and $\lambda \epsilon_{i}+u_{i}$ in Eq. (6.3), and $\rho=\lambda / \sqrt{2\left(\lambda^{2}+1\right)}$ where $\rho$ is identified by $\lambda$.
} 


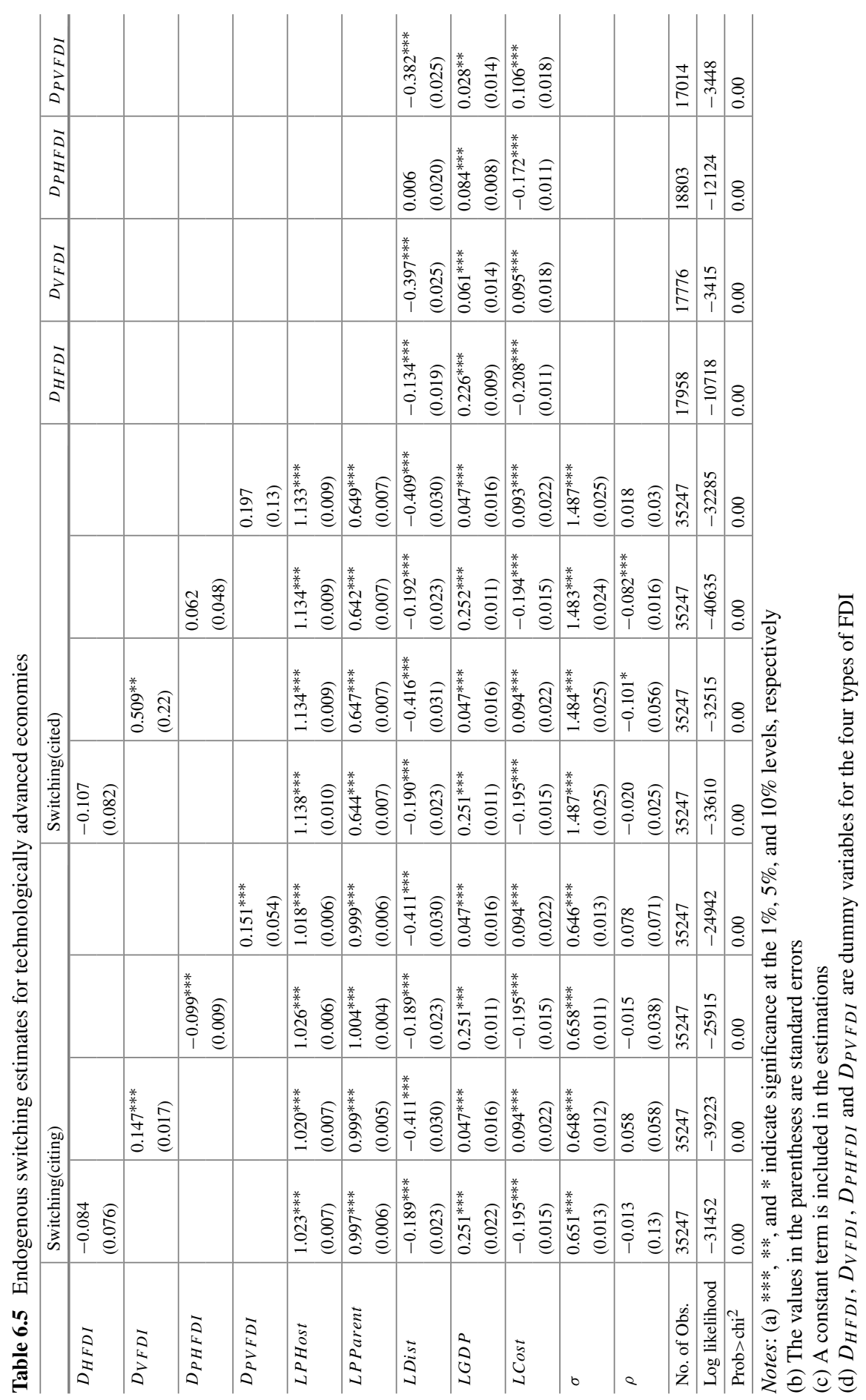


the host economies. As observed for $D_{H F D I}$ and $D_{P H F D I}$, the estimates become insignificant and significantly negative for citing, respectively.

Our findings imply that, for technologically advanced economies, "pure" VFDI is associated with significant technology spillovers even if we control for endogenous issues.

\subsubsection{Alternative Estimations}

To check the robustness of the basic findings in Sect.6.4.1, we conduct alternative estimations for Group I countries by adding explanatory variables. We include $P R O X$ (technological proximity), CapRatio (capital ratio), and Close (a dummy for industrial classification, which is one for the same sector and zero otherwise). We also include L Dist (the logarithm of the distance between Japan and host countries) and Year which captures the changes in citations.

Japanese parent companies and firms in their host countries may increase their citations of each other just because Japanese parent companies and firms in their host countries change the focus of their research activities in ways that bring them "closer" to each other in the technology space (Branstetter, 2006). To control for this issue, we include a measure of technological proximity $(P R O X)$ in the regression. As suggested by Jaffe (1986) and Branstetter (2006), $P R O X$ is constructed by

$$
\operatorname{PROX} X_{i}=\frac{F_{i} F_{\text {host }, i}^{\prime}}{\left(F_{i} F_{i}^{\prime}\right)\left(F_{\text {host }, i} F_{\text {host }, i}^{\prime}\right)},
$$

where $F_{i}=\left(f_{1 i}, \cdots, f_{k i}\right)$ is a vector of the cumulative count of patents obtained by affiliate $i$ 's parent firm in $k$ th technical area ${ }^{21}$ and $F_{\text {host }, i}$ is a vector of the aggregate count of patens obtained by all firms in the host country in which affiliate $i$ is located.

The literature on the role of affiliate ownership in technology spillovers is limited. There are a few studies focused on the correlation between productivity and the ownership of affiliates. Javorcik (2004) and Javorcik and Spatareanu (2008) found that the correlation of productivity with FDI is stronger if the affiliate is only partially, and not fully foreign owned, because joint ownership generates more technology transfer, and wholly owned affiliates employ more sophisticated technology that is out of reach of the average domestic supplier. As indicated by Keller (2010), however, the technology gap may be a key reason for differential effects for wholly versus partially owned affiliates. CapRatio, which is the share of affiliate capital owned by Japanese parent companies, is included to test the effects of ownership of affiliates on technology spillovers.

As in Sect. 6.4.1, we use patent citations at the USPTO as the dependent variable and employ the negative binomial model for our estimation. The estimated results

${ }^{21}$ We aggregate the US patent classes into 44 fields derived by Schmoch et al.(2003). 
are presented in Table 6.6..$^{22}$ The coefficients of $P R O X$ are significantly positive in all cases of citing and cited. These results confirm the findings in Branstetter (2006). The coefficients of Close are significantly positive in technology spillovers from host economies to Japanese MNEs, which implies that Japanese parent companies cite more patents of host economies when their affiliates run a business that is the same as or close to that of the parents. However, this is not the case for technology spillovers from Japanese MNEs to host economies, since the coefficients of Close are significantly negative. The ownership variable, CapRatio, has positive coefficients that are mostly significant, which implies that a higher share of ownership of foreign affiliates by Japanese parent companies tends to facilitate technology spillovers in both directions between Japanese MNEs and their host economies.

The estimates of $H F D I, V F D I, P H F D I$, and $P V F D I$ for the USPTO give similar results to those we observed in Table 6.4, except for $P H F D I$ and $P V F D I$ in the cited. Specifically, the significantly positive effect of $P V F D I$ is not robust for some combinations of explanatory variables.

\subsection{A Simple Model of FDI and Technology Spillovers}

To explain the observed relationship between the structure of FDI and technology spillovers in the previous section, we develop a partial-equilibrium model of FDI and technology spillovers among developed economies. We consider a world of two countries, home and foreign. Foreign variables are denoted by an asterisk.

We focus on the market for a differentiated good $x$. Consumers in the two countries share the same preference. The preference of the representative consumer takes the standard Dixit-Stiglitz form (Dixit and Stiglitz, 1977):

$$
U=\left(\sum_{j=1}^{N} x_{j}^{\alpha}\right)^{1 / \alpha}
$$

where $x_{j}$ is the consumption of a variety $j$ of $\operatorname{good} x, \alpha=1-1 / \sigma, \sigma>1$ is the elasticity of substitution across varieties, and $N$ is the total number of varieties supplied in the home market. We also assume that the market size is the same in the two countries.

The demand for a variety $j$ of good $x$ in the home country is given by

$$
x_{j}=\left(p_{j}^{c}\right)^{-\sigma} P^{\sigma-1} E,
$$

\footnotetext{
${ }^{22}$ Here, we only report the estimated results with full sets of explanatory variables. The results with various combinations of the explanatory variables are available from the corresponding author upon request.
} 


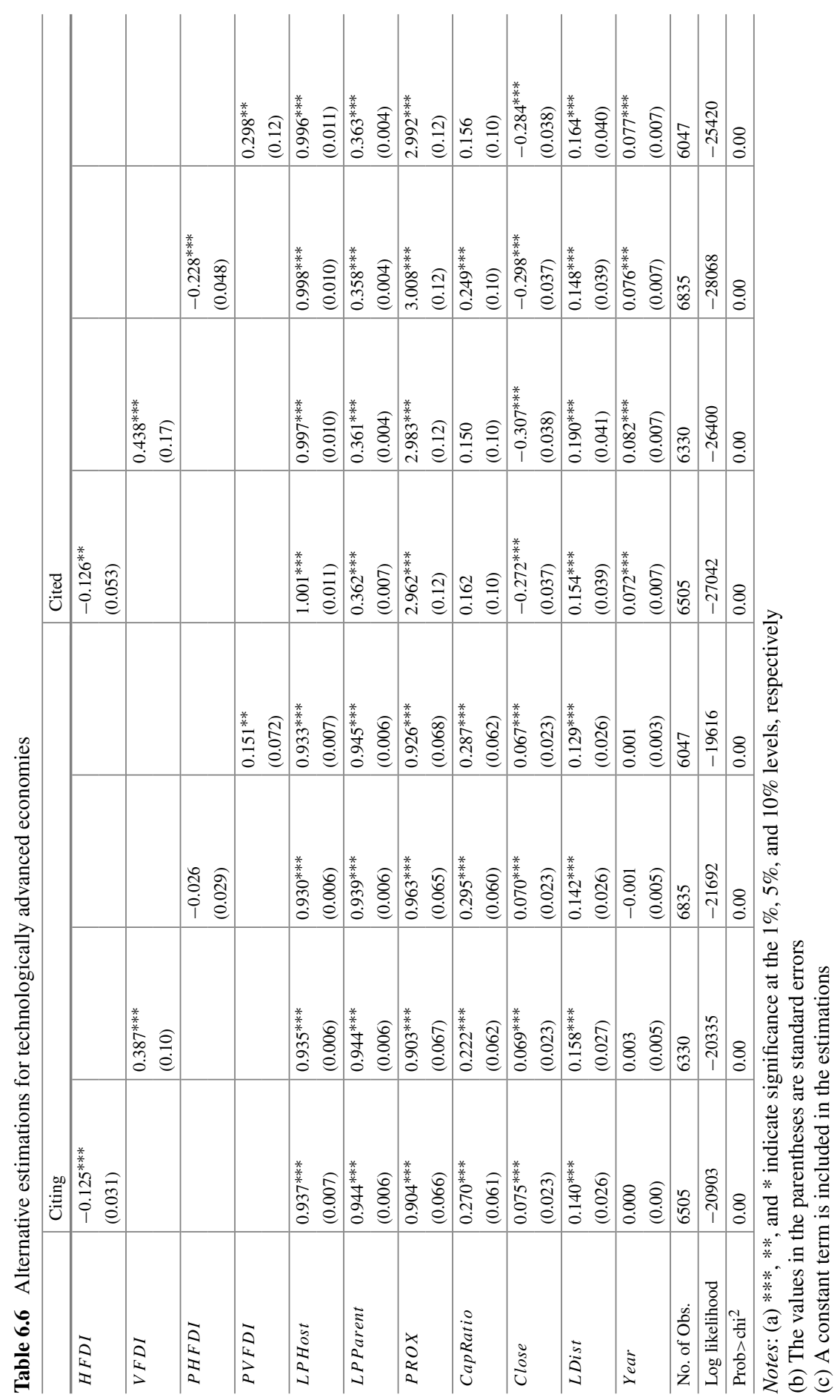


where $E$ is the total expenditure on $\operatorname{good} x$ in the home country (which is the same for the foreign country), $p_{j}^{c}$ is the CIF price of variety $j$ produced by a home firm and $P$ is the price index for the $x$ sector goods, which is defined as

$$
P=\left[\sum_{j=1}^{n}\left(p_{j}^{c}\right)^{1-\sigma}+\sum_{k=1}^{n^{*}}\left(p_{k}^{* c}\right)^{1-\sigma}\right]^{1 /(1-\sigma)},
$$

where $n$ and $n^{*}$ are the numbers of varieties produced by the home firms and the foreign firms, respectively, with $n+n^{*}=N$, and $p_{k}^{* c}$ is the CIF price of variety $k$ produced by a foreign firm.

In each country, there is one primary factor of production, labor, denoted by $l$. The wage rate, $w$, is the same in the two countries, i.e., $w=w^{*} \equiv \omega$. Labor is immobile across countries.

\subsubsection{Production and Supply}

Good $x$ is differentiated by variety and is supplied by monopolistically competitive firms. Each firm produces one variety. The nationality of a firm is identified by the location of its headquarters.

Good $x$ is produced in three sequential stages. ${ }^{23}$ Intermediate inputs for good $x$ are specific to varieties, and hence there is no market for its intermediate inputs. For simplicity we assume away the possibility of outsourcing production of intermediate inputs. All of the three production stages must be conducted in house, although firms can offshore some or all of the production stages by establishing affiliates in the other country.

The first stage of production is simply conducted by using only labor, so that one unit of an intermediate input $m_{1}$ is produced by one unit of labor: $m_{1}=l_{1}$. The quality of the intermediate input may be differentiated. It is $\theta_{1}$ if the first stage is performed in the home country and $\theta_{1}^{*}$ if it is in the foreign country, where $0<\theta_{1} \leq 1$ and $0<$ $\theta_{1}^{*} \leq 1$. The quality of $m_{1}$ matters when it is used in the second stage of production. The production function of an intermediate product is given by $m_{2}=\left(\theta_{1} m_{1}\right)^{\gamma} l_{2}^{1-\gamma}$, where $m_{2}$ stands for an intermediate product in the second stage and $\gamma \in(0,1)$. In the production function of $m_{2}, \theta_{1}$ is replaced by $\theta_{1}^{*}$ if $m_{1}$ produced in the foreign country is used. Moreover, in the final stage of production, $m_{2}$ and labor are used to produce a variety $j$ of good $x: x_{j}=\left(\theta_{2} m_{2}\right)^{\gamma} l_{3}^{1-\gamma}$, where the quality of $m_{2}$ is $\theta_{2}\left(\theta_{2}^{*}\right)$ if the second stage of production is performed in the home (foreign) country, where $0<\theta_{2} \leq 1$ and $0<\theta_{2}^{*} \leq 1$. A difference in the quality of intermediate inputs $m_{1}$ and $m_{2}$ reflects the technology gap for the particular production stage between the two

${ }^{23}$ This means that we consider the "snake" type in the terminology of Baldwin and Venables (2013). 
countries. ${ }^{24}$ Note that the location of the production stage rather than the nationality of firms determines the quality of intermediate inputs. This may be because the information on the technology of producing intermediate inputs is locally spilled over, while it is not spilled over across countries. ${ }^{25}$ Since the final good $x$ is not differentiated in quality, the location of the final production stage does not affect characteristics of varieties.

Iceberg transportation costs apply to cross-country shipment of both intermediate inputs and final goods. For one unit of an intermediate input and a final good to arrive at a foreign destination, $\tau \geq 1$ units of an intermediate input and $t \geq 1$ units of the final good must be sent, respectively.

When a firm sets up a production stage in the country different from the country in which its headquarters is located, it engages in FDI and incurs an extra fixed cost of $\Phi / 3$ units of labor per stage, where $\Phi>0$ is exogenously given and constant.

Each monopolistically competitive firm chooses both the location of the three production stages and the price for its own variety in each market, taking the price index as given. As is well known, a monopolistically competitive firm charges a constant mark-up over the unit cost of the final good, which is given by $p_{j}=C_{j} / \alpha$, where $p_{j}$ is the FOB price of variety $j$ and $C_{j}$ is the unit cost of producing variety $j$, which will be shown in detail below.

\subsubsection{Technology Spillovers}

We introduce the possibility of technology spillovers. Suppose that the quality of intermediate inputs can be upgraded by $R \& D$. We suppose that the outcome of $R \& D$ is stochastic. Consequently, the difference in the quality of intermediate inputs arises, depending on whether R\&D was successful or not. ${ }^{26}$

We take up the effects of spillovers from one firm's R\&D outcome to other firms' product stage. As is well known, technology spillovers occur from a firm with higher technology to a firm with lower technology. We assume that when a firm uses a better quality of an $i$ th-stage intermediate input for the production of the $(i+1)$ th stage, the information on the better quality of an $i$ th-stage intermediate input is spilled over to the $(i+1)$ th stage and improves the productivity of $\mathrm{R} \& \mathrm{D}$ for the $(i+1)$ th-stage intermediate input.

Under the above assumptions, the following lemma on spillovers holds.

\footnotetext{
${ }^{24}$ For our purpose of this chapter, we do not need to specify the cause of the technology gap between the two countries. Then, we assume that there is a technology gap between the two countries.

${ }^{25}$ This is different from technology spillovers that we will discuss below.

${ }^{26}$ The purpose of our analysis in this section is to investigate the relationship between types of FDI and technology spillovers. For this, we want to show how the technology gap between the two countries is related to FDI types and how it is also related to technology spillovers. But, we do not need to specify the details of R\&D and the production in the next period after spillovers occur.
} 
Lemma 6.1 Technology spillovers occur only if the ith and the $(i+1)$ th stages are located in different countries.

The reason is straightforward. If the $i$ th and the $(i+1)$ th stages are located in the same country, then all firms produce the same quality of the $i$ th-stage intermediate inputs and use them at the $(i+1)$ th stage. Thus, there is no scope for technology spillovers.

One may think that technology spillovers in our model are associated with imports of intermediate inputs with better quality. However, since each intermediate input is specialized to each variety in our model, inter-firm trade of intermediate inputs does not occur. Moreover, we can argue that technology spillovers through FDI are stronger than those through imports of intermediate inputs, because FDI involves various activities more than just the transaction of intermediate inputs.

\subsubsection{FDI and Technology Spillovers: HFDI}

We next analyze how firms locate production stages and how international technology spillovers are associated with FDI.

We define horizontal and vertical FDI in the following way. If a firm conducts the final stage in both the home and the foreign countries, it engages in HFDI. On the other hand, if a firm conducts either or both of the first two stages in the country that is different from the country in which its headquarters is located without conducting the final stage in that country, it engages in VFDI.

We focus on the representative firm whose headquarters is located in the home country. We call it "the home firm." All firms with the same nationality behave in the same way.

We first look at HFDI. We denote the combination of locations for three production stages by three capital letters. For example, if the first stage is located in the home country, the second stage is in the foreign country, and the final stage is in the home country, then we denote this combination by $H F H$. Then, the possible patterns of HFDI for the home firm are $\{F F F, H F F, H H F, F H F\}$. by

The unit cost function to serve the foreign market by the pattern of $F F F$ is given

$$
C_{F F F}\left(\omega ; \theta_{1}^{*}, \theta_{2}^{*}\right)=B\left(\left(\theta_{1}^{*}\right)^{-\gamma}\left(\theta_{2}^{*}\right)^{-1}\right)^{\gamma} \omega
$$

where $B \equiv\left\{\gamma^{\gamma}(1-\gamma)^{1-\gamma}\right\}^{-(1+\gamma)}$ is a constant. Similarly, the unit cost functions to serve the foreign market by the patterns of $H F F$ and $H H F$ are given by, respectively,

$$
\begin{aligned}
& C_{H F F}\left(\omega, \tau ; \theta_{1}, \theta_{2}^{*}\right)=B\left(\tau^{\gamma} \theta_{1}^{-\gamma}\left(\theta_{2}^{*}\right)^{-1}\right)^{\gamma} \omega, \\
& C_{H H F}\left(\omega, \tau ; \theta_{1}, \theta_{2}\right)=B\left(\tau \theta_{1}^{-\gamma} \theta_{2}^{-1}\right)^{\gamma} \omega .
\end{aligned}
$$


Moreover, the unit cost function to serve the foreign market by exporting from the home country is

$$
C_{H H H}\left(\omega ; \theta_{1}, \theta_{2}\right)=B\left(\left(\theta_{1}\right)^{-\gamma}\left(\theta_{2}\right)^{-1}\right)^{\gamma} \omega,
$$

where the transport costs for the shipment of the final good are not included.

In the analysis of the optimal configuration of production for the foreign market, it turns out that the configuration for the home market does not matter. Thus, we just focus on the profits from supplying to the foreign market. Given the demand for a variety and pricing policy under monopolistic competition, profits of the home firm from supplying a variety to the foreign market by the patterns $F F F, H F F, H H F$, and $H H H$ are given by, respectively,

$$
\begin{aligned}
\pi_{F F F} & =\frac{\alpha^{\sigma-1} E\left(P^{*}\right)^{\sigma-1}}{\sigma}\left(C_{F F F}\right)^{1-\sigma}-\Phi \omega, \\
\pi_{H F F} & =\frac{\alpha^{\sigma-1} E\left(P^{*}\right)^{\sigma-1}}{\sigma}\left(C_{H F F}\right)^{1-\sigma}-\frac{2}{3} \Phi \omega, \\
\pi_{H H F} & =\frac{\alpha^{\sigma-1} E\left(P^{*}\right)^{\sigma-1}}{\sigma}\left(C_{H H F}\right)^{1-\sigma}-\frac{1}{3} \Phi \omega, \\
\pi_{H H H} & =\frac{\alpha^{\sigma-1} E\left(P^{*}\right)^{\sigma-1}}{\sigma}\left(t C_{H H H}\right)^{1-\sigma} .
\end{aligned}
$$

Note that since $F H F$ is dominated by $H H F$ and $H F F$ for $\theta_{i}=\theta_{i}^{*}=1$ for $i=1,2$, we can exclude $F H F$ from our analysis. Then, the following lemma is obtained.

Lemma 6.2 Suppose that $\theta_{i}=\theta_{i}^{*}=1, i=1,2$. The home firm still has an incentive to engage in HFDI if $t>\tau^{\gamma}$ and $\Phi$ is sufficiently low.

Proof It is sufficient to prove that

$$
\pi_{H H H} \leq \max \left\{\pi_{F F F}, \pi_{H F F}, \pi_{H H F}\right\}
$$

holds when $\theta_{i}=\theta_{i}^{*}=1, i=1,2$. Since we focus on the incentive for one firm to choose a particular production configuration and since an individual firm takes the price index as given, we treat the price index as fixed. Then, define $A \equiv$ $\alpha^{\sigma-1} E\left(P^{*}\right)^{\sigma-1} B^{1-\sigma} / \sigma$ and $\phi \equiv \Phi \omega / A$. Substitute Eqs. (6.9)-(6.12) and Eqs. (6.5)(6.8) into Eq. (6.13) and rearrange terms to yield

$$
\begin{aligned}
\phi \omega^{\sigma-1} \leq & \max \left\{\left(1-t^{1-\sigma}\right),\left(\tau^{\gamma^{2}(1-\sigma)}-t^{1-\sigma}+\frac{1}{3} \phi \omega^{\sigma-1}\right),\right. \\
& \left.\left(\tau^{\gamma(1-\sigma)}-t^{1-\sigma}+\frac{2}{3} \phi \omega^{\sigma-1}\right)\right\}
\end{aligned}
$$

defining the upper bound of $\Phi$. Equation (6.14) is satisfied if 


$$
\begin{aligned}
\phi \omega^{\sigma-1} & \leq 1-t^{1-\sigma}, \\
\phi \omega^{\sigma-1} & \leq \frac{3}{2}\left(\tau^{\gamma^{2}(1-\sigma)}-t^{1-\sigma}\right), \quad \text { or } \\
\phi \omega^{\sigma-1} & \leq 3\left(\tau^{\gamma(1-\sigma)}-t^{1-\sigma}\right)
\end{aligned}
$$

holds, which requires that $\Phi=\phi A / \omega$ is sufficiently low for the above inequalities to hold. Since $\gamma \in(0,1)$ and $\sigma>1$, it holds that $\tau^{\gamma(1-\sigma)}<\tau^{\gamma^{2}(1-\sigma)}<1$ for $\tau>1$. Thus, we need $\tau^{\gamma(1-\sigma)}>t^{1-\sigma}$ or $t>\tau^{\gamma}$. Q.E.D.

This lemma implies that even without technology differences, firms have an incentive to engage in HFDI if transportation costs for the cross-border shipment of the final goods are sufficiently high and the additional fixed costs for FDI are sufficiently low. This is just the standard motive for the HFDI. Lemma 6.2 yields the following proposition.

Proposition 6.1 HFDI does not necessarily induce technology spillovers.

Proof From Lemma 6.2, HFDI occurs even in the case of no technology difference. If the technology level is the same across countries, then there is no possibility of technology spillovers. Q.E.D.

When the production configuration is $H F F$, the first and the second stages are located in different countries. Thus, Lemma 6.1 suggests that technology spillovers may occur. However, the proof of Lemma 6.2 shows that $H F F$ can be the optimal configuration even in the absence of a technology gap. If this is the case, technology spillovers do not occur in the case of $H F F$.

\subsubsection{FDI and Technology Spillovers: VFDI}

We turn to the case of VFDI. In this case, the home firm conducts the final stage only in the home country, so that the possible patterns of VFDI are $\{F H H, F F H, H F H\}$. We obtain the following lemma.

Lemma 6.3 Suppose that $\theta_{i}=\theta_{i}^{*}=1$ for $i=1,2$. Then, the home firm has no incentive to engage in VFDI as long as $\tau$ and $\Phi$ are positive.

Proof By definition, the home firm conducts the final stage in the home country for any type of VFDI. We need to examine the supply to the home market. Then, compared to the national integration (i.e., the pattern of $H H H$ ), FDI in either or both of the first two stages incurs additional transportation costs and fixed costs of FDI. Thus, in the absence of technology advantage in the foreign production, VFDI always increases production costs as long as $\tau$ and $\Phi$ are positive. Q.E.D.

This lemma implies that in the absence of a factor cost differential, firms have no incentive to engage in VFDI without a technology difference as long as there are positive transportation costs for intermediate inputs and FDI requires additional fixed costs. 
Now, the unit cost functions for the home firm in VFDI are given by

$$
\begin{aligned}
& C_{H F H}\left(\omega, \tau ; \theta_{1}, \theta_{2}^{*}\right)=B\left(\tau^{1+\gamma} \theta_{1}^{-\gamma}\left(\theta_{2}^{*}\right)^{-1}\right)^{\gamma} \omega, \\
& C_{F F H}\left(\omega, \tau ; \theta_{1}^{*}, \theta_{2}^{*}\right)=B\left(\tau\left(\theta_{1}^{*}\right)^{-\gamma}\left(\theta_{2}^{*}\right)^{-1}\right)^{\gamma} \omega, \\
& C_{F H H}\left(\omega, \tau ; \theta_{1}^{*}, \theta_{2}\right)=B\left(\tau^{\gamma}\left(\theta_{1}^{*}\right)^{-\gamma} \theta_{2}^{-1}\right)^{\gamma} \omega .
\end{aligned}
$$

In order to simplify the analysis, we assume that $t=1$, so that firms have no incentive to locate the final stage of production for the foreign market separately from that for the home market. It is then shown that as long as the final stage is performed in a single location, firms have no incentive to conduct either or both of the first two stages at more than one location. Given this, profits of the home firm in production configurations $k=H F H, F F H, F H H$, and $H H H$ are given by, respectively.

$$
\begin{aligned}
\Pi_{H F H} & =\frac{\alpha^{\sigma-1} E\left\{(P)^{\sigma-1}+\left(P^{*}\right)^{\sigma-1}\right\}}{\sigma}\left(C_{H F H}\right)^{1-\sigma}-\frac{1}{3} \Phi \omega, \\
\Pi_{F F H} & =\frac{\alpha^{\sigma-1} E\left\{(P)^{\sigma-1}+\left(P^{*}\right)^{\sigma-1}\right\}}{\sigma}\left(C_{F F H}\right)^{1-\sigma}-\frac{2}{3} \Phi \omega, \\
\Pi_{F H H} & =\frac{\alpha^{\sigma-1} E\left\{(P)^{\sigma-1}+\left(P^{*}\right)^{\sigma-1}\right\}}{\sigma}\left(C_{F H H}\right)^{1-\sigma}-\frac{1}{3} \Phi \omega, \\
\Pi_{H H H} & =\frac{\alpha^{\sigma-1} E\left\{(P)^{\sigma-1}+\left(P^{*}\right)^{\sigma-1}\right\}}{\sigma}\left(C_{H H H}\right)^{1-\sigma},
\end{aligned}
$$

where $\Pi_{k}$ denotes the home firm's total profits when it engages in VFDI with configuration $k$. Then, we can prove the following proposition on the relationship between VFDI and technology spillovers. ${ }^{27}$

Proposition 6.2 VFDI of the configuration HF H by the home firm may induce technology spillovers in both directions. Other types of VFDI can induce technology spillovers in one direction.

Proof First, we derive the conditions for $H F H$ to be chosen. Define $G \equiv$ $\alpha^{\sigma-1} E\left\{(P)^{\sigma-1}+\left(P^{*}\right)^{\sigma-1}\right\} B^{1-\sigma} / \sigma$ and $\psi \equiv \Phi \omega / G$. It is shown from Eqs. (6.8), (6.15), (6.18), and (6.21) that $\Pi_{H F H} \geq \Pi_{H H H}$ holds if and only if

$$
\left(\theta_{2}^{*} / \tau^{1+\gamma}\right)^{\gamma(\sigma-1)}-\left(\theta_{2}\right)^{\gamma(\sigma-1)} \geq \frac{\omega^{\sigma-1} \psi}{3\left(\theta_{1}\right)^{\gamma^{2}(\sigma-1)}} .
$$

It is also shown from Eqs. (6.15), (6.16), (6.18), and (6.19) that $\Pi_{H F H} \geq \Pi_{F F H}$ holds if and only if

\footnotetext{
${ }^{27}$ To simplify the analysis, we assume that firms treat technology spillovers as pure externality and do not take the effects of technology spillovers into account in their decision on production locations. Including technology spillovers in firms' profits will not alter the qualitative results.
} 


$$
\left(\theta_{1}^{*}\right)^{\gamma^{2}(\sigma-1)}-\left(\theta_{1} / \tau\right)^{\gamma^{2}(\sigma-1)} \leq \frac{\omega^{\sigma-1} \psi}{3\left(\theta_{2}^{*} / \tau\right)^{\gamma(\sigma-1)}}
$$

and from Eqs. (6.15), (6.17), (6.18), and (6.20) that $\Pi_{H F H} \geq \Pi_{F H H}$ holds if and only if

$$
\left(\theta_{1}\right)^{\gamma}\left(\theta_{2}^{*} / \tau\right) \geq\left(\theta_{1}^{*}\right)^{\gamma} \theta_{2}
$$

Since $\theta_{2}<\theta_{2}^{*}$ is necessary for Eq. (6.22) to hold, Lemma 6.1 implies that technology spillovers in R\&D occur for $m_{2}$ from the foreign country to the home country. On the other hand, $\theta_{1}<\theta_{1}^{*}$ can be consistent with the inequality Eq. (6.23) if the gap between $\theta_{1}$ and $\theta_{1}^{*}$ is sufficiently small, $\tau$ is sufficiently low, and $\psi$ is sufficiently high. Thus, the technology spillovers in R\&D for $m_{1}$ from the home country to the foreign country may not occur. On the other hand, if $\theta_{1}>\theta_{1}^{*}$ holds, however, they do occur. It is easy to prove that $\theta_{1}>\theta_{1}^{*}$ and $\theta_{2}<\theta_{2}^{*}$ satisfy Eq. (6.24) and that $\theta_{1}<\theta_{1}^{*}$ and $\theta_{2}<\theta_{2}^{*}$ can satisfy Eq. (6.24) if $\theta_{1}^{*} \leq\left(\theta_{2}^{*} / \tau \theta_{2}\right)^{1 / \gamma} \theta_{1}$ holds. Moreover, in order for Eqs. (6.22) and (6.23) to hold simultaneously, we need

$$
\left(\left(\theta_{1}^{*}\right)^{\gamma}\left(\theta_{2}^{*} / \tau\right)\right)^{\gamma(\sigma-1)}+\left(\left(\theta_{1}\right)^{\gamma} \theta_{2}\right)^{\gamma(\sigma-1)} \leq 2\left(\left(\theta_{1} / \tau\right)^{\gamma}\left(\theta_{2}^{*} / \tau\right)\right)^{\gamma(\sigma-1)},
$$

which can be consistent with Eq. (6.24).

We next derive the conditions for $F H H$ to be chosen. It is shown from Eqs. (6.8), (6.17), (6.20), and (6.21) that $\Pi_{F H H} \geq \Pi_{H H H}$ holds if and only if

$$
\left(\theta_{1}^{*} / \tau\right)^{\gamma^{2}(\sigma-1)}-\left(\theta_{1}\right)^{\gamma^{2}(\sigma-1)} \geq \frac{\omega^{\sigma-1} \psi}{3\left(\theta_{2}\right)^{\gamma(\sigma-1)}} .
$$

It is also shown from Eqs. (6.16), (6.17), (6.19), and (6.20) that $\Pi_{F H H} \geq \Pi_{F F H}$ holds if and only if

$$
\left(\theta_{2}^{*} / \tau\right)^{\gamma(\sigma-1)}-\left(\theta_{2} / \tau^{\gamma}\right)^{\gamma(\sigma-1)} \leq \frac{\omega^{\sigma-1} \psi}{3\left(\theta_{1}^{*}\right)^{\gamma^{2}(\sigma-1)}}
$$

and from Eqs. (6.15), (6.17), (6.18), and (6.20) that $\Pi_{F H H} \geq \Pi_{H F H}$ holds if and only if

$$
\left(\theta_{1}\right)^{\gamma}\left(\theta_{2}^{*} / \tau\right) \leq\left(\theta_{1}^{*}\right)^{\gamma} \theta_{2}
$$

In order for Eqs. (6.25) and (6.26) to hold simultaneously, we need

$$
\left(\left(\theta_{1}^{*}\right)^{\gamma}\left(\theta_{2}^{*} / \tau\right)\right)^{\gamma(\sigma-1)}+\left(\left(\theta_{1}\right)^{\gamma} \theta_{2}\right)^{\gamma(\sigma-1)} \leq 2\left(\left(\theta_{1}^{*} / \tau\right)^{\gamma} \theta_{2}\right)^{\gamma(\sigma-1)},
$$

which can be consistent with Eq. (6.27). Since $\theta_{1}<\theta_{1}^{*}$ is necessary for Eq. (6.25) to hold and satisfies Eq. (6.27), this implies from Lemma 6.1 that technology spillovers in R\&D occur for $m_{1}$ from the foreign country to the home country. 
We finally derive the conditions for $F F H$ to be chosen. It yields from Eqs. (6.8), (6.16), (6.19), and (6.21) that $\Pi_{F F H} \geq \Pi_{H H H}$ holds if and only if

$$
\left(\left(\theta_{1}^{*}\right)^{\gamma}\left(\theta_{2}^{*} / \tau\right)\right)^{\gamma(\sigma-1)}-\left(\theta_{1}^{\gamma} \theta_{2}\right)^{\gamma(\sigma-1)} \geq \frac{2 \omega^{\sigma-1} \psi}{3} .
$$

Also, from Eqs. (6.16), (6.17), (6.19), and (6.20) it holds that $\Pi_{F F H} \geq \Pi_{F H H}$ if and only if

$$
\left(\theta_{2}^{*} / \tau\right)^{\gamma(\sigma-1)}-\left(\theta_{2} / \tau^{\gamma}\right)^{\gamma(\sigma-1)} \geq \frac{\omega^{\sigma-1} \psi}{3\left(\theta_{1}^{*}\right)^{\gamma^{2}(\sigma-1)}}
$$

and from Eqs. (6.15), (6.16), (6.18), and (6.19) it holds that $\Pi_{F F H} \geq \Pi_{H F H}$ if and only if

$$
\left(\theta_{1}^{*}\right)^{\gamma^{2}(\sigma-1)}-\left(\theta_{1} / \tau\right)^{\gamma^{2}(\sigma-1)} \geq \frac{\omega^{\sigma-1} \psi}{3\left(\theta_{2}^{*} / \tau\right)^{\gamma(\sigma-1)}} .
$$

Since $\theta_{2}<\theta_{2}^{*}$ is necessary for Eq. (6.29) to hold and satisfies Eq. (6.28), this implies from Lemma 6.1 that technology spillovers occur in R\&D for $m_{2}$ from the foreign country to the home country. Q.E.D.

This proposition shows that if home firms engage in VFDI in the configuration of $H F H$, technology spillovers occur from the foreign country to the home country. Technology spillovers in the opposite direction may also occur but do not necessarily. For other types of VFDI, we expect that technology spillovers occur only in one direction from the foreign country to the home country.

Note that if the wage rates between the two countries are sufficiently different, then firms may have an incentive to engage in VFDI even in the absence of a technology difference, but VFDI does not induce international technology spillovers. This situation corresponds to the typical North-South VFDI rather than the North-North VFDI. Then, this never undermines our argument on the relationship between VFDI and technology spillovers. That is, North-South VFDI does not necessarily involve international technology spillovers.

\subsection{Conclusion}

In this chapter, we have investigated how the structure of MNEs' activities affects technology spillovers between MNEs and their host countries by using detailed firmlevel data on Japanese MNEs and patent citation data. We propose new specifications of FDI by information on sales and purchases of foreign affiliates of MNEs. We define pure HFDI as FDI with a high share of both purchases of intermediate inputs and sales of outputs in the local market and pure VFDI as FDI with a high share of transactions (i.e., both purchases of intermediate inputs and sales of outputs) with the home country. In addition, partially horizontal and partially vertical FDI are defined. 
Our estimation results reveal that when a technologically advanced country hosts Japanese MNEs, an increase in the degree of pure VFDI has a significantly positive effect on technology spillovers as measured by patent citations in both directions between the host country and Japanese MNEs. In contrast, pure HFDI has no significant effect or significantly negative effects on technology spillovers in either direction. We also find that VFDI by Japanese firms to technologically advanced countries is not based on factor price differentials.

To explain the mechanism for the observed relationship between the structure of FDI and technology spillovers, we have developed a simple model of FDI and technology spillovers, in which a good is produced in multiple stages. Our model reveals that VFDI among technologically advanced economies would be associated with international technology spillovers, while HFDI does not necessarily induce technology spillovers.

The results indicate that technology spillovers from FDI occur among technologically advanced economies. In particular, VFDI plays an important role in technology spillovers. We come to the conclusion that technologically advanced countries can gain knowledge flow from MNEs' activities both as the home country and as the host country when FDI involves the geographical fragmentation of the production process.

Another finding of this chapter is that when the host country is a technologically less advanced country, any types of FDI do not have positive effects on technology spillovers. One possible explanation for this finding is that we have focused on technology spillovers measured by patent citations. Since patent applications are made to be counted as "spillovers," indigenous firms in technologically less advanced countries do not largely benefit from technology spillovers in our definition. Another possible explanation for the finding is that it reflects the stringency of intellectual property right (IPR) protection in host countries. Branstetter et al. (2006) and Wakasugi and Ito (2009) find that the stronger protection of IPR in host countries has a positive effect on technology transfer from parent firms to their foreign affiliates. Nagaoka (2009) also finds a positive effect of stronger patent protection on expanding the scope of the recipients of technology transfer. Taking these empirical findings into account, we notice that the weaker protection of IPR in developing countries generally hinders technology spillovers from FDI in our measurement.

Since our findings are based on Japanese MNEs' data, we suggest testing whether our findings could be applicable to other countries' MNEs through examining detailed data on MNEs in other countries. 
Open Access This chapter is licensed under the terms of the Creative Commons Attribution 4.0 International License (http://creativecommons.org/licenses/by/4.0/), which permits use, sharing, adaptation, distribution and reproduction in any medium or format, as long as you give appropriate credit to the original author(s) and the source, provide a link to the Creative Commons license and indicate if changes were made.

The images or other third party material in this chapter are included in the chapter's Creative Commons license, unless indicated otherwise in a credit line to the material. If material is not included in the chapter's Creative Commons license and your intended use is not permitted by statutory regulation or exceeds the permitted use, you will need to obtain permission directly from the copyright holder. 